\title{
Research on Teaching and Training Strategy for English Consecutive Interpretation
}

\author{
Bo Ni \\ School of Foreign Studies, Xi'an University, Xi'an, Shaanxi, 710065
}

Keywords: teaching; training strategy; consecutive interpretation; English

\begin{abstract}
English Consecutive interpretation is a new discipline that has been established and developed with the needs of professional construction and the needs of economic and social development. It has a strong vitality and tremendous potential for development. The consecutive interpretation teaching in colleges and universities is an important approach and main position for training interpreters. At the same time, it is also an inevitable requirement for expanding and deepening the professional development level. This paper mainly discusses the teaching of English interpretation. First of all, this paper clarifies the problems existing in the English consecutive interpretation teaching, namely: the problem of teaching mode, the problem of teaching methods, the problem of teaching evaluation, and the problem of teaching equipment; then it analyzes the three principles that should be grasped in the teaching of interpretation; This paper has combined with related theories such as Gestalt to provide practical and easy-to-follow teaching suggestions, namely: to strengthen retelling, reading and recitation exercises, and to establish to improve interpreting skills. "Objective" teaching model of interpreting and "student-centered" situational teaching mode, establishing an evaluation system for interpreting teaching and learning, and building a new type of speech classroom.
\end{abstract}

\section{Introduction}

Since the reform and opening up, China's economic development has gradually entered the right track, forming a close relationship with the development of the world economy. The demand for English interpreters is increasing in society, and more stringent requirements and standards are also put forward for the simultaneous interpretation of English. In order to better improve students' English interpreting ability, major universities continue to innovate in English training and learning methods, and use advanced teaching methods in order to better improve the quality of the English interpreter education and meet the development requirements of the talent market.

After the interpreter, speaks some or all of the utterances in the original utterances and the interpreter can use the linguistic expression to convey the audience's ideas and emotions to the audience in a verbal form. It is based on the linguistic symbolization of the original language, and the understanding of the meaning of the original language is obtained through the interpretation of the linguistic symbolic expression. The complete process of cross-interpretation generally includes the five stages of information receiving, decoding (maintaining, coding, and expressing). The final output of the interpreter is closely related to the above five stages and has a positive proportional relationship. Translators can only achieve considerable skills in the five stages of interpretation, and can use these skills appropriately in impeccable interpreting practice. The "technical work" of the item can be completed more satisfactorily [1].

\section{Problems in the Teaching of English Consecutive Interpretation}

The Ministry of Education's Higher Education and Foreign Languages Teaching Steering Committee in May 2005 made interpreting classes one of the required courses for English majors to study in senior grades. The course aims to develop students' basic interpreting skills, be familiar with the basic theory of interpreting, and be able to carry out consecutive interpreting of topics in a smooth and continuous manner. With the acceleration of China's internationalization process, 
"interpreting" has become more and more a buzzword and interpreters have become increasingly dependent on them. Therefore, this move by the Ministry of Education is indeed a timely rain. However, successive interpretation teaching is a brand-new attempt after all. The following problems and shortcomings should be fully considered.

In general, the teaching of consecutive interpreting mainly revolves around the development of thematic teaching mode. A large number of interpreting teaching materials and counseling books are also written in this form. Interpreting teaching is often conducted in the same manner as each topic. These topics relate to education, tourism, health, environment, technology, medical care, and so on. This teaching mode is called thematic teaching mode. Therefore, in interpreting training and teaching, students should be taught "interpreting skills" as their main training principles, supplemented by texts with different themes to strengthen interpreting skills. For example, this model helps students to accumulate a large number of thematic vocabulary and expression, and basically covers the interpreting practice in the main areas of reality. However, this model is similar to the sea tactics, with emphasis on the transfer of language knowledge, and the development of students' interpreting skills is insufficient [2].

Based on the opinions of the above experts, the author believes that, on the basis of language training, the goal of "cultivating students' interpreting skills awareness" should be the goal pursued by the interpretation teaching. However, interpreting teaching often becomes a general language training class. For example, the interpreting class is a listening class, a translation class, an oral class, and an intensive reading class. The teacher's role in interpretation teaching is to explain the language knowledge to students, help students modify grammatical errors in the translation, practice speaking, and so on. Of course, these exercises should be done, and should be done more often in the early stages of students' learning to interpret. After all, a solid language foundation cannot be replaced by any skill. However, it should be noted that these exercises cannot substitute the training of interpretation skills. The purpose of these exercises should be to lay the groundwork for the development of interpretation skills.

Interpreting teaching ultimately requires a more systematic and objective assessment of the student's actual interpreting level. On the one hand, students are made aware of their own deficiencies and give directions for their own improvement; on the other hand, they also accumulate experience for future interpreting teaching. The theoretical and practical exploration provides real data. Therefore, a scientific, effective and objective assessment of the quality of interpretation teaching is critical. However, the quality evaluation of interpreting teaching often has a strong subjective color, and lacks a relatively uniform, scientific, detailed and objective evaluation system. In addition, the quality evaluation of interpreting teaching is generally conducted by listening and recording. This assessment method is easy to operate and saves time. However, the interpreting practice under this method has some distance from the practice of actual interpretation. In addition, listening to recordings can only be used to judge students' interpreting levels and cannot be used to make comprehensive judgments on students. The author believes that assessing translators' level of interpreting should not only be based on judging their language level and bilingual translation ability, but must also take into account the translator's ability to adapt on the spot, voice, expression, deportment, interpreter professional ethics, comprehensive performance, and many other aspects. And these aspects of the latter are precisely not reflected in the recording.

The traditional voice classrooms are lined up one by one, and are extremely crowded. Students are separated from each other. Teachers and students and students and students cannot achieve a good interaction. Teachers are also difficult to rearrange. Students monitor and manage. Actual consecutive interpreting is generally face-to-face communication between people, and is influenced by a number of factors, such as the speaker's body language, the atmosphere of the scene, and the relationship between the two parties. It is difficult for traditional voice classrooms to express such an atmosphere. Teachers often put tapes and students do translations. At this point, the tape acts as a speaker in the actual interpreting, so that the interaction between the interpreter and the speaker in the interpreting classroom evolves into a dialogue between the student and the machine. 


\section{The Principle of Consecutive Interpretation}

The most important principle of interpreting is the meaning of translation, not the conversion of linguistic signs, but through the understanding of the source language, to express the meaning of the source language as quickly, accurately, and completely as possible in the target language so that others understand the source language. In the process of learning English interpreting, it is necessary to clearly observe the principle of consecutive interpretation, so that the timeliness, accuracy, one-time, and initiative of the consecutive interpreting can be achieved [3].

The timeliness of interpretation directly determines the level and quality of English interpretation. In practical work, the English interpreter's translation and listening are basically completed at the same time. After the information is input to the brain, the recipient needs to organize the translation language in a timely manner. In a short period of time, the logic and level of language will be planned and delivered to the needy. Translation accuracy is guaranteed at the instant of completion of translation, and accuracy is also an important factor in the quality of interpretation. The interpreter needs to find out whether the content of the translation is correct in the translation process according to the needs of translation, especially for some professional English content or professional words, etc., must be transmitted to the listener with accuracy and completeness. Interpreters also need to pay attention to one-off features, and the interpreters' communication is basically completed at one time. The interpreters need to ensure that the linguistic organization is orderly during the interpretation, and the information can be accurately conveyed at one time. The principle of initiative is an important point in interpreting learning and training. In the process of interpreting, students need to actively think about what they hear, actively predict what the speaker is saying, actively organize and understand the content, and ensure that the interpreter can fully understand the content. Learn what you need to translate.

\section{English Interpreting Learning and Training Optimization Measures}

The most basic factor in interpreting is firstly accuracy, followed by fluency. Accuracy is a prerequisite for fluent expression and is the most basic constituent factor of interpreting [4]. The main process of interpreting includes source language speech listening, comprehension memory, and target language translation output. Speech listening and understanding is the premise and the prerequisite for translation of the target language. During the training of listening, you need to be proficient in the ability to accurately distinguish the English language structure, English accent, writing logic, different English presentation habits and the use of English grammar, which can correctly identify the grammatical errors or unclear content. For English interpreters, during the training period, they not only need to continuously perform extensive listening training, master the content of the subject, understand the background knowledge, but also need to continuously expand the subject matter. The subjects involve economic, political, cultural, social, educational and religious issues in all aspects.

As far as the pronunciation is concerned, British and American pronunciation still have some differences. Then misunderstandings happen. Familiarity with different English accents requires a lot of practice and summary. In the process of listening training, we must not only extensively cover all fields for extensive listening, but also insist on listening and writing while listening, which can deepen students' understanding of English and improve their listening ability.

Note-taking seems to be a mystery to untrained students, but it can be obtained through a great deal of practice and self-creation. It can imitate predecessors' notes at first, and can gradually create your own note symbols when you are familiar with them. Generally speaking, when taking notes, the English initials and abbreviation can be used to express the meanings of words. Chinese characters can be used to represent the sidelines. Exclamation points can be used to indicate important points or warnings. Symbols can also be combined with letters and radicals. If you say "yesterday", you can add a little to the left of the initial letter "d" of "day," and tomorrow you can add a little to the right of "d," and so on, adding "two days ago" to "the day before yesterday." "Last week," "last month," "last year," etc., will change the first letter accordingly. This speeds up the 
speed of notes and makes it easier to remember and read notes.

Consecutive interpreters mainly have the following two kinds of memory training methods. The first is the shadow-reading training method. This method is to read the source language at almost the same speed while playing the recording. At the same time, it grasps the pauses, intonations, and tone, etc., and reads and records the mind while training. In the process, exercise your own thinking ability, use the meaning of the vocabulary to extend the expression of the whole sentence, or hear a central vocabulary to analyze the content that you want to describe next [5].

The second training method is retelling. After listening to the recording of an article, it retells its general meaning with the source language and the target language respectively. This not only helps memory training but also trains students to grasp key information. The article logically memorizes and extrapolates the content of the article.

The third training method is mainly aimed at long-term memory. It reads according to the original content such as articles or news, and uses English to describe it proficiently. This method does not limit the time for training materials, but it needs to pay attention to the selected content and the expression Focus.

The last and most crucial step in the successful interpretation is to communicate and use the target language to express the speaker's meaning accurately and fluently. In addition to having good English language skills, students also need to strengthen their Chinese language skills. In the training of language organization ability, it is necessary to start from the aspects of digital translation exercises, the improvement of adaptability, the use of common words, and the overview of vocabulary, etc., to continuously improve the students' language ability and bilingual interpretation ability, and to improve the quality of the teaching of consecutive interpreting.

\section{Conclusion}

The teaching and training of consecutive interpreting should master basic theories and practice a lot, to improve their own interpreting skills. The teaching and training of consecutive interpreting should be gradual and progressive, and organically combine the various aspects of interpreting to enhance comprehension, memory, and expressiveness, and to constantly expand knowledge. Those who have lofty intentions have become successful. Facts have proved that as long as the method is appropriate, and the trainers can insist on for a long time, the training of the simultaneous interpretation of English will surely succeed.

\section{Acknowledgements}

Fund Project: Xi'an University of Arts and Sciences 2018 Key Course Project. Project Name: Consecutive Interpretation. Project Number: KGB201815

\section{References}

[1] Zhong Weihe. Interpreting Training: Modes, Contents, Methods [J]. Chinese Translation, 2001(3):30-33.

[2] Li Jun. How to Better Interpret Training [J]. Chinese Science \& Technology Translation, 2010 (2):20-23.

[3] Cao Rongping, Chen Yaping. Formative Assessment and Its Application in Interpretation Teaching [J]. Chinese Translation, 2013(1):45-50.

[4] Gao Huai. Translation Teaching Research: Theory and Practice [M]. Hangzhou: Zhejiang University Press, 2008. 66

[5] Liu Yuqing. Research on the Theory of Interpreting and Translating [M]. China Foreign Translation and Publishing Company, 2004. 58 